\title{
Managing patients with substance use disorders: reflections of a medical trainee
}

\section{La prise en charge des patients souffrant de troubles liés à la toxicomanie : réflexions d'un étudiant en médecine}

\author{
Flora Jung ${ }^{1}$ \\ ${ }^{1}$ Faculty of Medicine, University of Toronto, Ontario, Canada \\ Correspondence to: Flora Jung; email: flora.jung@mail.utoronto.ca \\ Published ahead of issue: January 7, 2021; published: February 26, 2021. CMEJ 2021, 12(1) Available at http://www.cmej.ca \\ (C) 2021 Jung; licensee Synergies Partners
}

https://doi.org/10.36834/cmej.70075 This is an Open Journal Systems article distributed under the terms of the Creative Commons Attribution License https://creativecommons.org/licenses/by-nc-nd/4.0) which permits unrestricted use, distribution, and reproduction in any medium, provided the original work is properly cited.

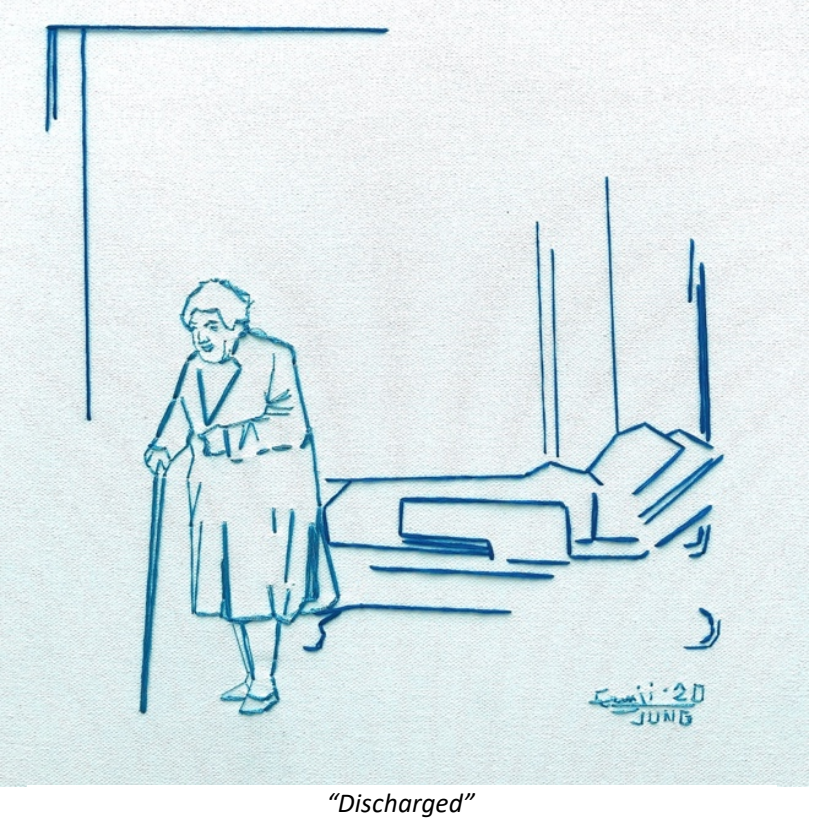

During my rotation on a medicine service, I met with many patients who were determined to change the unfolding paths of their lives. Although each had an incredible story, one lingered long in my mind. This patient was struggling with an opioid addiction in the context of severe depression and anxiety, which together had a profound impact on their motivation.

I intenviewed this patient each morning and left each one frustrated. It was clear to me that they recognized the need for change in their habits- "this isn't the life I want to live anymore," "this addiction has ruined my life," "I can't go back to how I used to be." But whenever I attempted to elicit what steps they could take to best achieve abstinence, they replied "I just don't know." Any recommendation I had, however small, was struck down fiercely with one excuse after another. I was lost in their inertia and took home each day a corrosive sense of failure.

I thought of this art piece hoping it would allow me to consolidate those feelings. To create "Discharged," I started with a 14"x14" cotton canvas, using embroidery techniques and suturing instruments to stitch in blue yarn.

This piece took much longer and was much harder than I had anticipated and frankly had hoped. Canvas is meant to be painted, not to be punctured and sewn together a hundred times over. My yarn was thick, and my needle was dull. There was still the buzzing anticipation of the pride and catharsis of finishing this piece, but there were many weeks during its construction where it languished untouched and hidden in a corner of my room, silent and incomplete.

After many stitches, I realized that through this project I was coming to understand my patient's experience. Who doesn't want the promises of sobriety? Who doesn't want to feel good and content and fulfilled? Yet in spite of our wants and dreams, overcoming addiction is a fight against one's own brain and one gets pulled back into the pit. Freedom requires bending our most familiar tools in the most unfamiliar ways, and our own bodies single-mindedly marshal both mental and physical forces in resisting. My patient exclaimed to me one day, why should I not stop attending therapy or discharge 
themself or even end my own life? It would be easier, they said. It would be more natural. Every step on their path towards change was through a deep trench of thick mud and it seemed no one could help. As desperately as they wanted to reach the end, they were exhausted and could not take another desperate step closer.

My struggles with my art thus came to symbolize a simple solidarity with my patient. Each forced stitch with conventional materials used in unconventional ways represented another forced step my patient took to stitch their own life back together.

My patient did improve, as far as I followed them. I worked hard to address each of their stressors-from hours spent with the pharmacist to optimize their antidepressant to tracking down a nail clipper from across the hospital (which, as marginal as this act may have been to their overall management, I believe, earned me the patient's trust and engagement). We formed a close therapeutic relationship and my efforts on their behalf seemed to help them realize that their life was worth their own time and effort.

I now recognize I was largely able to invest so much into this patient because I was a trainee. I have the benefit of seeing only a handful of patients each day and I am eager to learn and to help. I could imagine how therapeutic relationships if unfettered by time would similarly improve the outcomes of their patients.

What I want to remember most from this interaction was not the frustration or fatigue from the process, but the pride I felt when the patient finally began to engage and the joy in watching them leave on the day of discharge. There is something wonderful about seeing a made bed in an empty room, as the patient leaves with confidence they won't return. I look fondly back at this art piece to recollect what makes the challenges of health care all worth it in the end. 